\title{
Distribution and neurochemical characteristic of the cardiac nerve structures in the heart of chinchilla (Chinchilla laniger Molina)
}

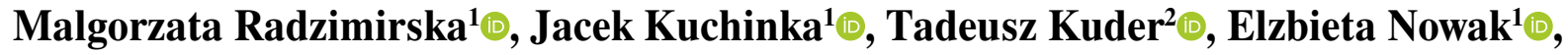 \\ Wojciech Trybus $^{1}{ }^{\oplus}$, Grzegorz Wrobel $^{2}{ }^{\oplus}$, Aleksander Szczurkowski ${ }^{1}{ }^{\oplus}$
}

${ }^{1}$ Department of Medical Biology, Institute of Biology, Jan Kochanowski University in Kielce, Kielce, Poland ${ }^{2}$ Department of Anatomy, Collegium Medicum, Jan Kochanowski University in Kielce, Kielce, Poland

\begin{abstract}
Introduction. The heart innervation is made up of plexo-ganglionic formation containing sympathetic, parasympathetic, and sensory components. We examined the distribution and neurochemical coding of the ganglia and nerve fibers in the chinchilla's heart.

Material and methods. The heart sections of 10 male and 10 female adult chinchillas were processed in accordance with the thiocholine method for acetylcholine esterase (AChE), and the SPG method for detecting the presence of adrenergic fibers was applied. The routine technique of immunohistochemical (IHC) staining with primary antibodies directed against ChAT, VAChT, D $\beta \mathrm{H}, \mathrm{TH}$, CART, NPY, VIP, GAL and SOM was used. The secondary antibodies were conjugated with Alexa Fluor 488 and Alexa Fluor 555 fluorophores.

Results. The epicardium contained ganglia and nerve fibers, the myocardium had a few ganglion neurocytes and nerve fibers, and the endocardium contained only nerve fibers. In the epicardium, AChE-positive fibers were more prevalent than SPG-positive fibers. All the ganglion cells were immunopositive for ChAT and VAChT. Some cells also had a positive reaction to $\mathrm{D} \beta \mathrm{H}$ and $\mathrm{TH}$. Fibers containing cholinergic and adrenergic markers were numerous, while many of them were ChAT/D $\beta \mathrm{H}$ - and VAChT/TH-positive. CART/NPY and CART/VIP, as well as CART and GAL, were observed to be colocalized in ganglion neurocytes, as well as in individual cells. The nerve fibers were found to contain all the neurotransmitters we tested for, as well as the following co-occurrences: ChAT/D $\beta \mathrm{H}, \mathrm{VAChT} / \mathrm{TH}, \mathrm{CART} / \mathrm{NPY}, \mathrm{CART} /$ /VIP, CART/GAL, and CART/SOM.

Conclusions. Our analysis of the neurochemical profile of the nerve structures in chinchilla's heart showed that, despite interspecies differences, the general pattern of the distribution of autonomic nervous system structures is similar to that of other mammals' species, including humans. (Folia Histochemica et Cytobiologica 2021, Vol. 59, No. 3, 157-166)
\end{abstract}

Key words: chinchilla; cardiac innervation; histochemistry; immunohistochemistry

Correspondence address: Aleksander Szczurkowski, PhD, DrSc. Department of Medical Biology, Institute of Biology,

Jan Kochanowski University in Kielce,

7 Uniwersytecka St., 25-406 Kielce, Poland

tel.: +48413496313

e-mail: aleksander.szczurkowski@ujk.edu.pl

\section{Introduction}

The cardiac nervous system is made up of a series of plexo-ganglionic formations and contains sympathetic, parasympathetic, and sensory components. The autonomic components, however, are the main components regulating functions of cardiomyocytes, the conductive system, and the blood vessels. The sympathetic components make up a system that stimulates the cardiomyocytes of the heart muscle and of 
the heart conduction system through the release of neurotransmitters at nerve endings (noradrenaline NA, neuropeptide Y - NPY, galanin - GAL, and nitric oxide synthase - NOS). The parasympathetic part acts with a different set of neurotransmitters (acetylcholine - ACh, cocaine- and amphetamine-regulated transcript - CART, and vasoactive intestinal polypeptide - VIP) to inhibit heart function [1-5].

The innervation of the heart has been studied in many species of animals from different taxonomic classes. The majority of studies have been carried out on the small mammals, particularly on laboratory rodents, and the intrinsic cardiac nervous system in rat has been studied at the molecular level [6]. Moreover, investigations have been carried out on farm species [7]. A few papers also described the morphology, topography, and physiology of the human cardiac ganglia [8-15].

The ganglia are mainly located in the strategic regions of the heart: around the sinoatrial and atrioventricular nodes, the main vessels of the heart, and the region of the coronary sulcus. In this respect, there is usually significant interspecific variation, but even so, the general pattern of distribution is similar in both humans and other mammalian species [11, 14, 16].

Our results indicate that there may be several subpopulations of neurocytes in myocardial ganglia, containing various combinations of neurotransmitters. The neurons of the cardiac ganglia are thus not phenotypically and functionally homogeneous but constitute a neurochemical complex that goes beyond the classical picture of parasympathetic ganglia $[5,17,18]$.

The chinchilla often is used as an animal model for many types of investigations related to the dysfunction of human organs such as middle ear [19], uterus [20], digestive system and lungs [21]. But there is a lack of detailed data on the autonomic nervous system of its heart. Research to date has only provided incomplete information on the morphology and topography of the parasympathetic ganglia in this species [22]. There have also been descriptions of adrenergic and cholinergic innervation of the atrioventricular valves [23] and pancreas [24]. However, there is no data available on the neurochemical analysis of ganglionic cells, nor is there detailed information available on the innervation of the heart muscle (including the types of fiber) in the chinchilla. It thus seems advisable to carry out a thorough analysis of the neural structures of the chinchilla's heart, both in terms of topography and neurochemical profile. This is the first study of this specific topic. Our results are important in both their theoretical and practical aspects.

\section{Material and methods}

We investigated twenty adult (10 months old) chinchillas (Chinchilla laniger Molina, 1782) of both sexes (10 males and 10 females, weight $400-600 \mathrm{~g}$ ). Animals were collected immediately after industrial slaughter. The research conformed to the requirements of Act for the Protection of Animals Used for Scientific or Educational Purposes (15 January 2015). Studies of tissues obtained post-mortem do not require the approval of an ethics committee. We performed morphological investigation of the atria and ventricles of the heart using the acetylcholinesterase (AChE) $[25,26]$ and SPG [27] histochemical techniques, as well as routine single and double staining immunohistochemistry.

Material sampling and histochemistry. Ten individuals (5 males and 5 females) were used for histochemical investigations. Immediately after slaughter, in appropriately adapted room, under stereo microscope control (Nikon SMA 800) the anterior wall of the chests was opened, and hearts were collected removing the pericardial sac. Next, heart tissues were rinsed in physiological solution and fixed for 30 minutes in $10 \%$ buffered formalin. During the fixation, collected material was transported to the Department of Medical Biology of Jan Kochanowski University in Kielce, Poland, where the other procedures were performed. A separate microdissection of the atria and ventricles was used to prepare whole mount specimens. Flat atrial preparation was carried out in the following manner. The atria and ventricles were separated along the atrioventricular groove and the aorta, and the pulmonary trunk was gently detached. Cholinergic positive structures were investigated with AChE method. The macromorphological (whole mount) specimens were treated in the incubated solution at $\mathrm{pH} 6.4-6.8$ and temperature $37^{\circ} \mathrm{C}$ (acetyl thiocholine iodide, acetate buffer, sodium citrate, cooper sulfate, distilled water, potassium ferricyanide). The activity of the pseudocholine nonspecific esterase was blocked using iso-OMPA. Next, the tissues were rinsed in distilled water, and ammonium sulfide was added to intensify the reaction and the specimens were mounted in DPX.

The adrenergic structures were investigated using the SPG (sucrose-phosphate-glyoxylic acid) method. Briefly, whole-mount specimens were immersed in SPG solution for 5 seconds (reagents: glyoxylic acid monohydrate, sucrose, potassium phosphate monobasic), dried under a cold stream of air for $10 \mathrm{~min}$, and heated to $95^{\circ} \mathrm{C}$ for $3 \mathrm{~min}$. Specimens were observed using fluorescence microscope Nikon 90i (Nikon, Tokyo, Japan) and digital pictures were taken with Nikon Digital Sight SD-L1 system using NIS-Elements 3.22 software.

Immunohistochemistry. The chests of ten individuals (5 males and 5 females) were opened and the left ventri- 
Table 1. Primary antisera used in the research

\begin{tabular}{|l|c|c|c|c|c|}
\hline Antigen & Host & Type & Dilution & Catalog No. & Supplier \\
\hline ChAT & Goat & Polyclonal & $1: 100$ & NBP1-30052 & Novus Biologicals, Cambridge, UK \\
\hline VAChT & Rabbit & Polyclonal & $1: 1000$ & EUD261 & Acris Antibodies, San Diego, CA, USA \\
\hline DBH & Rabbit & Polyclonal & $1: 500$ & NBP1-78349 & Novus Biologicals, Cambridge, UK \\
\hline TH & Mouse & Monoclonal & $1: 500$ & MAB318 & Millipore, Temecula, CA, USA \\
\hline CART & Mouse & Monoclonal & $1: 2000$ & MAB163 & R\&D System, Minneapolis, MN, USA \\
\hline NPY & Rabbit & Polyclonal & $1: 2000$ & AHP2189 & AbD Serotec, Hercules, CA, USA \\
\hline VIP & Rabbit & Polyclonal & $1: 2000$ & Ab22736 & Abcam, Cambridge, UK \\
\hline GAL & Rabbit & polyclonal & $1: 1000$ & AB2233 & Millipore, Temecula, CA, USA \\
\hline SOM & Rabbit & polyclonal & $1: 1500$ & $8330-0154$ & AbD Serotec, Hercules, CA, USA \\
\hline
\end{tabular}

Abbreviations: ChAT — choline acetyltransferase, VAChT — vesicular acetylcholine transporter, D $\beta \mathrm{H}-$ dopamine $\beta$-hydroxylase, TH - tyrosine hydroxylase, CART — cocaine- and amphetamine-regulated transcript, NPY — neuropeptide Y, VIP — vasoactive intestinal polypeptide, GAL — galanin, SOM - somatostatin

Table 2. Secondary antisera used in the research

\begin{tabular}{|l|c|c|c|c|}
\hline Host & Fluorophore & Dilution & Catalog No. & Supplier \\
\hline Donkey anti-rabbit & Alexa Fluor 488 & $1: 500$ & A21206 & Invitrogen, Carlsbad, CA, USA \\
\hline Donkey anti-goat & Alexa Fluor 555 & $1: 500$ & A21432 & Invitrogen, Carlsbad, CA, USA \\
\hline Donkey anti-mouse & Alexa Fluor 555 & $1: 500$ & A31570 & Invitrogen, Carlsbad, CA, USA \\
\hline
\end{tabular}

cles were incised to insert cannula into the aorta, and the right cardiac auricle was then transected. Perfusion was performed using 0.41 of $4 \%$ ice-cold buffered paraformaldehyde ( $\mathrm{pH}$ 7.4) with perfusion apparatus [28]. Hearts were collected and additionally postfixed by immersion in the same fixative for $15 \mathrm{~min}$, rinsed with phosphate buffer, and transferred to and stored in $30 \%$ buffered sucrose solution for two weeks. Frozen slides $(8-10 \mu \mathrm{m})$ were prepared with the microtome (Shandon Cryotome E; Thermo Scientific, USA). Next, the specimens (whole mount specimens and sections) were processed for the single and double-labelling immunofluorescence method. Tissues were incubated for 16-20 $\mathrm{h}$ at room temperature with primary antibodies against choline acetyltransferase (ChAT), vesicular acetylcholine transporter (VAChT), dopamine $\beta$-hydroxylase $(\mathrm{D} \beta \mathrm{H})$, tyrosine hydroxylase $(\mathrm{TH})$, cocaine- and amphetamine-regulated transcript (CART), neuropeptide Y (NPY), vasoactive intestinal polypeptide (VIP), galanin (GAL), and somatostatin (SOM) (Table 1). Tissues were then next incubated with proper secondary antibodies conjugated with fluorochrome Alexa Fluor 488 and Alexa Fluor 555 (Table 2). After incubation, the specimens were coverslipped with buffered glycerol and examined under a fluorescent microscope with a confocal Nikon Eclipse Ti-A1R (Nikon Instruments Inc., NY, USA) attachment.

Control over the specificity of staining was obtained by preabsorbing a diluted antiserum with $20 \mu \mathrm{g} / \mathrm{ml}$ of an appropriate antigen, which completely abolished the specific immunoreactivity. In addition, we repeated the experiments with the primary antiserum replaced by nonimmune serum, or by phosphate buffered saline (PBS), in order to verify the specificity of particular immunoreactions.

\section{Results}

\section{Histochemistry}

Histochemical examination using the AChE method showed the presence of ganglia with different number of cells (from a dozen to several dozens) and individual ganglion cells in various regions of the epicardium of the atria of the heart. A smaller number of clusters of ganglionic neurocytes (7-10) were seen in the right atrium near the ostium of the cranial vena cava (Fig. 1A), and two dense clusters of cholinergic neurocytes were noted in the area of the right atrium auricle. On the other hand, several ganglia (3-5) composed of a few tens of cells were found on the surface of the left atrium near the ostia of the pulmonary veins (Fig. 1B). All these structures were connected to each other by a network of nerve fibers, which also showed a positive reaction to AChE. In this way, a kind of plexo-ganglionic cholinergic structure was formed, containing both larger structures and some structures of only a few cells mainly in the area of the sinoatrial node (Fig. 1C). We observed the connection of these plexoganglia with other similar structures located by the 


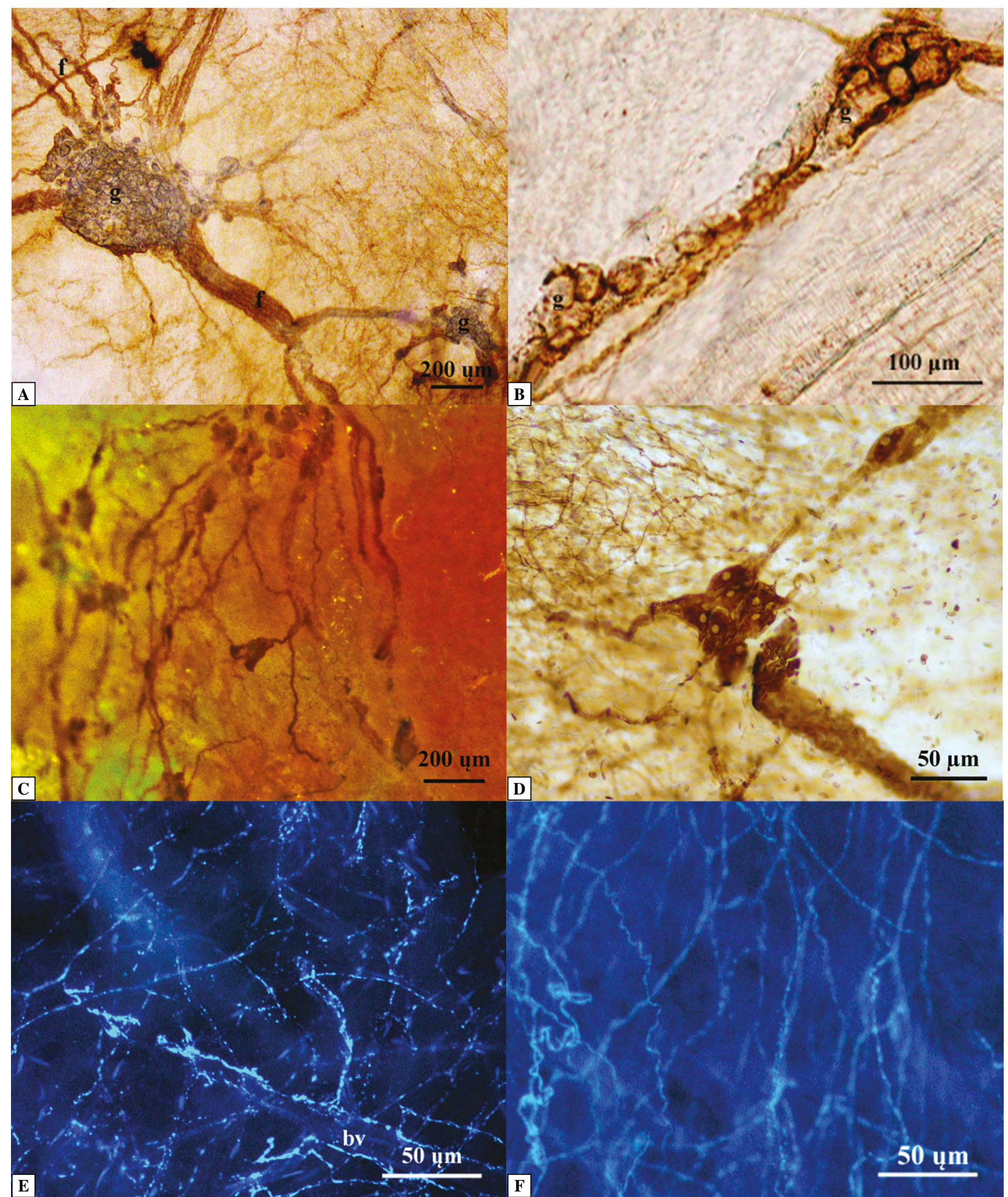

Figure 1. Structures of the autonomous nervous system in various regions of chinchilla's heart. A. The acetylcholinesterase (AChE)-positive ganglia in the epicardium of the right atrium near the ostium of the cranial vena cava. B. The elongated AChE-positive ganglion on the posterior surface of the left atrium near the ostia of the pulmonary veins. C. The AChE-positive plexo-ganglionic structures on the anterior surface of the right atrium in the area of the sinoatrial node. D. The AChE-positive fibers on the posterior surface of the right ventricle. E. The adrenergic nerve fibers in the epicardium of the left atrium along the blood vessels. F. The adrenergic plexus in the epicardium posterior wall of the right ventricle. Figures 1A-D were stained by histochemical AChE method, and Figs. 1E, F by the SPG-method as described in Methods. Legend: g — ganglion, bv — blood vessels, $\mathrm{f}$ - nerve fibers. 
right and left coronary sulci on the atrial facies of the heart. In the case of the epicardium of the ventricles, the ganglionic clusters were smaller, usually with only a few cells (Fig. 1D). The thickest AChE-positive bundles of fibers (about $100 \mu \mathrm{m}$ thickness) branched into thinner and thinner bundles (Fig. 1A). Significantly thinner fibers (below $50 \mu \mathrm{m}$ thickness) were seen on the surface of the ventricles in the vicinity of the coronary sulcus (Fig. 1D). The myocardium of both the atria and the ventricles contained individual neurocytes, and numerous fibers, while the endocardium contained only tiny nerve fibers.

The SPG method only revealed numerous adrenergic fibers located in the atria and ventricles, with characteristic varicosities (Fig. 1E, F). These formed a three-dimensional network in all layers of the heart, which was well developed, especially in the epicardium and myocardium. A particularly high density of SPG-positive fibers was observed in the adventitia of blood vessels (Fig. 1E). A dense neuronal network was also observed around the papillary muscles in the ventricles of the heart.

\section{Immunohistochemistry}

Immunohistochemical (IHC) methods allowed for a more detailed analysis of the innervation of the heart. Ganglia immunopositive to ChAT and VAChT were found, with various numbers of neurocytes (from a few to a few dozen) in the epicardium and myocardium of the atria and ventricles. The largest immunoreactive ChAT ganglia were observed near the ostium of the cranial vena cava in the epicardium of the right atrium (Fig. 2A) and on the surface of the left atrium in the vicinity ostia of the pulmonary veins. Strong immunopositivity to ChAT and VAChT was observed in numerous nerve fibers in all layers of the heart, in both atria and ventricles (Fig. 2A-D). The cholinergic fibers ran singly and also formed bundles of varying thickness. In the case of the enzymes of the catecholamine pathway, $\mathrm{D} \beta \mathrm{H}$ and $\mathrm{TH}$ immunoreactivity was observed in numerous fibers present in the epicardium, myocardium, and endocardium (Fig. 2B, D). Only a few ganglion cells (particularly those located in the atria) showed colocalization of ChAT and $\mathrm{D} \beta \mathrm{H}$ (Fig. 2A). VAChT and TH were colocalized in ganglion neurocytes (Fig. 2C), and numerous fibers showed ChAT/D $\beta \mathrm{H}$ and $\mathrm{VAChT} / \mathrm{TH}$ colocalization (Fig. 2B, D).

CART-immunopositive neural structure studies have shown the presence of this neuropeptide in numerous nerve fibers, in both the atria and in the ventricles of the heart (Fig. 3A-F). They were especially numerous in the epicardium and myocardium, where they formed a spatial network while in the endocardium, they were thin and sparse. CART-immunoreactivity of numerous nerve cells in the ganglia of the epicardium of the right ventricle and the right and left atrium was observed (Fig. 3A, C, D). We also noted individual cells and small CART-positive clusters of them in the atrial myocardium.

NPY was seen in numerous nerve fibers, which usually form a three-dimensional network in all three layers of the heart (Fig. 3A, B). In addition, NPY positive cells were seen in the ganglia of the atrial epicardium (Fig. 3A). The most abundant VIP-positive and GAL-positive nerve fibers were found in the epicardium and myocardium of both the atria and ventricles (Fig. 3C, D). The VIP-immunopositive fibers formed a dense, very fine network. In the outer layer of the left atrium, presence of GAL was observed in the neurocytes that form small clusters there (Fig. 3D). Multiple SOM-positive fibers of varying thickness were seen in all layers of the atria, and ventricles (Fig. 3E, F). The most numerous were present in the epicardium and myocardium of the left atrium, along the walls of blood vessels (Fig. 3E).

The CART/NPY, CART/VIP and CART/GAL neuropeptides were found to be colocalized in the cytoplasm of ganglion cells in the atrial epicardium, atria and ventricles (Fig. 3A, C, D). CART-immunopositive nerve fibers also showed colocation with NPY, especially in those along the blood vessels (Fig. 3B). The coexistence of CART and VIP, as well as of CART and GAL, was found the in epicardial and myocardial fibers (Fig. 3D). We observed CART- and SOM-immunopositive nerve fibers in the myocardium of the left atrium and ventricle, particularly in the vicinity of blood vessels (Fig. 3E, F).

\section{Discussion}

The regulation of the heart function by the autonomic nervous system has two main components: an adrenergic component, which stimulates the heart and conduction system, and a cholinergic component, which inhibits them $[29,30]$. It is also known that the sympathetic part consists mainly of nerve fibers, while the parasympathetic part involves both fibers and nerve cells. The situation is similar for the investigated species. However, despite numerous reports on the topic, the neurochemical nature of these neural structures in other mammals is not entirely clear. Some authors have indicated that there are several subpopulations of neurons in the ganglia of different neurochemical coding, and therefore also with different functional capabilities. The most common neurons are those with the classic cholinergic nature. A second group of cardiac neurons is of a dual neurochemical 


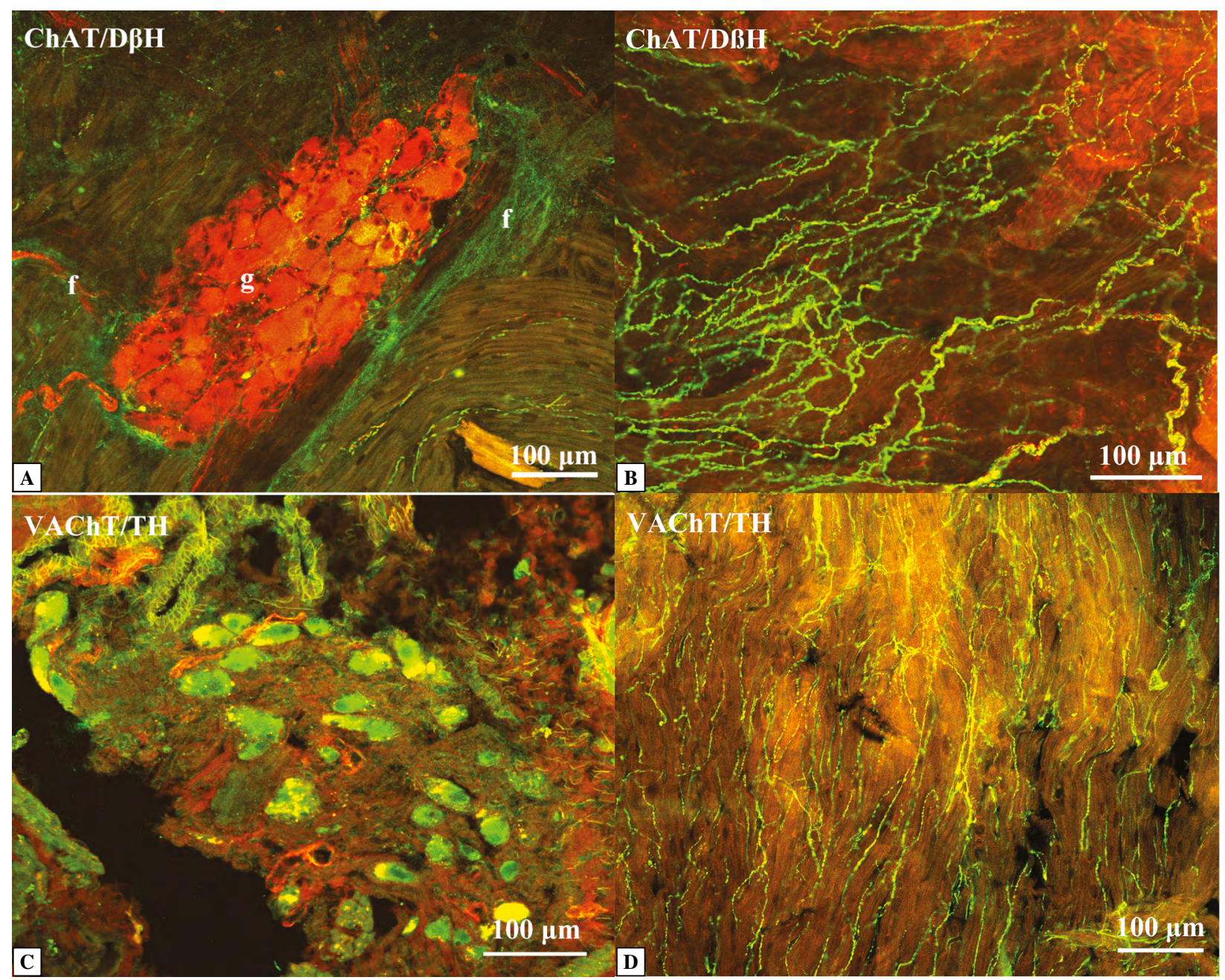

Figure 2. A. The autonomic ganglion and nerve fibers in the epicardium of chinchilla's right atrium $(\mathrm{ChAT}-\mathrm{red}, \mathrm{D} \beta \mathrm{H}-$ green; colocalization - gold/yellow; whole mount specimen). B. The cholinergic and adrenergic fibers in the epicardium of the left ventricle (ChAT — red, D $\beta \mathrm{H}$ - green; colocalization — gold/yellow; whole mount specimen). C. The agglomeration of neurocytes in the epicardium of the right atrium (VAChT — green, TH — red; colocalization — gold/yellow; frozen section). D. The distribution of the nerve fibers in the myocardium of the right ventricle (VAChT - green, TH - red; colocalization — gold/yellow; whole mount specimen). Immunohistochemical staining was performed as described in Methods. Legend: g — ganglion, bv — blood vessels, $\mathrm{f}$ - nerve fibers. Abbreviations as in the description of Table 1.

type: the main neurotransmitter is acetylcholine, but enzymes belonging to the catecholamine pathway are also present. There is a disagreement in the literature on the relative abundances of cholinergic and noncholinergic cells: Weihe et al. [18] suggested that $40-50 \%$ of rhesus and human cardiac neurons may contain enzymes of the catecholamine pathway. Singh et al. [11] showed similar results for humans. Haberberger and Kummer [31] found that all guinea pig cardiac neurons contained both choline acetyltransferase and B-2 adrenoreceptors. Rysevaite et al. [32] found in mouse only $4 \%$ of $\mathrm{TH}$-positive cells, and only $14 \%$ of ChAT and TH positive cells. Similar colocalization has been reported for rat and rabbit [33, 34].
A similar situation has been found for chinchilla, with only a small number of ganglionic neurocytes being immunoreactive to ChAT and $\mathrm{D} \beta \mathrm{H}$. Colocalization of these mediators was also found in nerve fibers where ChAT and TH were observed.

Recently, a number of papers have described the presence of the CART peptide in heart ganglia [35-38]. CART is known to be an anorexigenic peptide produced in brain, mainly in the hypothalamus. It has also been found in nerve endings in the digestive tract and in parasympathetic ganglia. Most reports have indicated that CART is present in the nerve fibers of the heart, although there have also been reports of its presence in cardiac neurons [35-37]. CART 


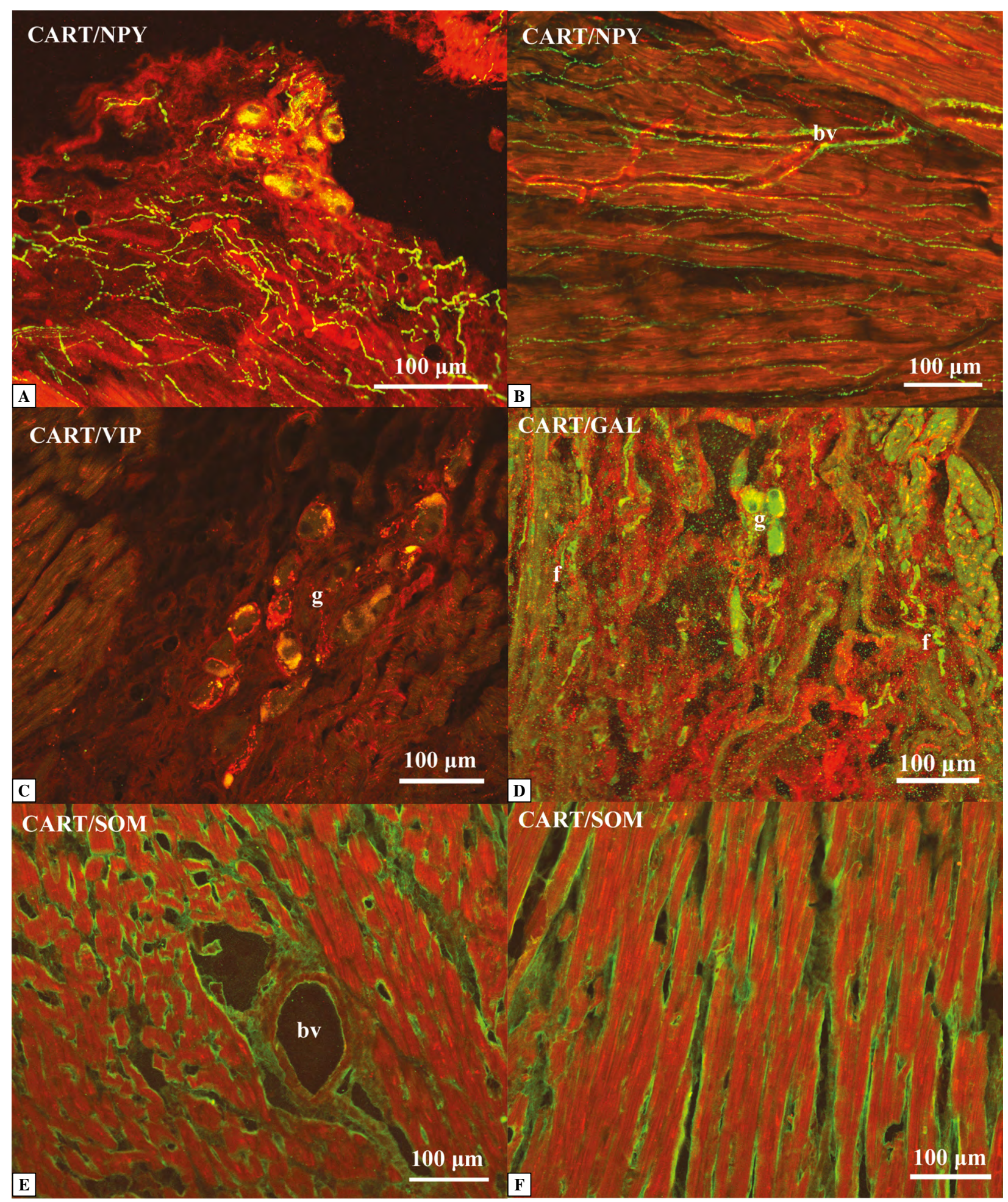

Figure 3. A. The agglomeration of the nerve cells and nerve fibers in the epicardium of chinchilla's right atrium (CART — red, NPY — green; colocalization — gold/yellow; frozen section). B. The nerve fibers along the blood vessels in the myocardium of the right atrium (CART — red, NPY — green; colocalization — gold/yellow; whole mount specimen). C. The small agglomeration of neurocytes in the myocardium of the left ventricle (CART - red, VIP - green; colocalization — gold/yellow; frozen section). D. The neurocytes and numerous nerve fibers in the epicardium of the left atrium (CART — red, GAL — green; colocalization — gold/yellow; frozen section). E-F. The numerous nerve fibers in the myocardium of the left atrium (E) and left ventricle (F) (CART — red, SOM — green; colocalization — gold/yellow; frozen section). IHC - method. Legend: $\mathrm{g}$ - ganglion, bv — blood vessels, $\mathrm{f}$ - nerve fibers. Abbreviations as in the description of Table 1. 
raises the blood pressure in the coronary arteries and increases the heart rate. Calupa et al. [35] showed that most guinea pig cardiac ganglia were innervated with immunoreactive CART nerve fibers. A few ganglion neurocytes have been found to be CART positive; these also contained ChAT or NOS. Richardson et al. [37] noted the presence of CART-immunoreactivity in $46 \%$ of rat cardiac neuron bodies, some of which also contained NOS or calbindin. The present study found a positive response to CART in the chinchilla's atrial ganglia. The colocalization of CART with NPY and GAL has also been observed in nerve fibers, especially along blood vessels. Some authors have suggested that CART protects mitochondrial DNA from oxidative stress [38]. NPY is an important peptide neurotransmitter involved in sympathetic activation. According to Richardson et al. [33], all rat cardiac neurons other than ChAT-positive contain NPY. The present study also found NPY in both the cells and the nerve fibers of the heart.

The vasoactive intestinal peptide (VIP) mainly affects the intestinal nervous system. Nevertheless, its presence has also been demonstrated in the heart ganglia. Horackova et al. [39] noted its presence in guinea pig heart. About $10 \%$ of neurocytes dispersed throughout the heart muscle were VIP-positive. Moravec et al. [40] did not find it in rat ganglionic neurons, while Parsons et al. [41] and Steele et al. [42] noted the coexistence of VIP and other neurotransmitters (NPY, SP, NOS) in guinea pig heart. In the investigated species, we did not find VIP in nerve cells, though numerous fibers were VIP-immunoreactive.

Galanin (GAL) is a neuropeptide that affects the metabolism by affecting the frequency of food consumption; it reduces energy expenditure, which promotes obesity [43]. It also participates in cardiovascular regulation causing an increase in blood pressure and tachycardia [44]. As shown by physiological studies conducted in guinea pigs, the galanin released from sympathetic neurons controls the heart's rate. Herring et al. [45] indicate that galanin receptors are found only in the right atrium. Our results revealed GAL both in the nerve cells and fibers in the epicardium of the left atrium of chinchilla's heart.

Somatostatin (SOM) is a neuropeptide present in many organs that is also involved in the regulation of the heart. It can occur alone or with AChE. The inhibitory function of SOM has been demonstrated for contractions of human heart muscle [42]. Day et al. [8] demonstrated that different regions of the rat heart (right atrium, right ventricle, and atrioventricular node) contain high concentrations of somatostatin. Its presence has also been found in the few cardiac endings of the guinea pig vagal nerve and in numerous subsets of cardiac neurons [36, 42].
Our study also found SOM in nerve fibers, mainly in the epicardium.

The neural structures in the heart (ganglia and plexuses) are found in the epicardium, myocardium, and endocardium. Clusters of neurocytes are found mainly in the epicardium, while a few loosely spaced cells are found in the myocardium; only nerve fibers are present in the endocardium. There are divergent data in the literature regarding the density of nerve fibers in particular parts of the heart. Crick et al. [46] found in pig that the density of nerve fibers in the epicardium and myocardium was greater in the ventricles (particularly in the left ventricle) than in the atria. In the endocardium they also noted a higher density of nerve fibers in the right ventricle and right atrium. A similar distribution of density of nerve structures in human hearts was described by Marron et al. [9]. Gordon et al. [47] showed a different pattern of density in the hearts of pig and domestic cattle: there was a greater density in the atria than in the ventricles, and greater density in the epicardium than in the endocardium. In the chinchilla a richer neural network of atrial epicardium was found, and in the endocardium of ventricles - especially in the papillary muscles. Taking into account the density of nerve fibers networks in the epicardium, we can state that in chinchilla the cholinergic network is denser than the adrenergic network. In the work of Kuchinka et al. [23] concerning innervation of atrioventricular valves in chinchilla, the opposite was found, with adrenergic innervation predominating over cholinergic.

To summarize, taking into account the colocalization of ChAT/D $\beta \mathrm{H}, \mathrm{VAChT} / \mathrm{TH}, \mathrm{CART} / \mathrm{NPY}$, CART/VIP, CART/GAL, and CART/SOM, the analysis of the neurochemical nature of the nerve structures in chinchilla's heart fits with the current model of the chemical code of the mammalian cardiac nervous system, despite some differences in the details. At the same time, studies on various mammalian species cardiac ganglia allow us to conclude that the pattern of innervation and neurochemical characteristics may serve as a model for human heart. An important piece of information in this context would seem to be provided by the relatively high proportion of neurotransmitters associated with sympathetic activation, which may contribute to an increase in catecholamine concentration in the heart, especially in people with cardiomyopathy $[48,49]$.

\section{References}

1. Forsgren S, Moravec M, Moravec J. Catecholamine-synthesizing enzymes and neuropeptides in rat heart epicardial ganglia; an immunohistochemical study. Histochem J. 1990; 22(12): 667-676, doi: 10.1007/BF01047451, indexed in $\mathrm{Pu}-$ bmed: 1706694 . 
2. Kuder T, Tekieli A. Gross and light microscopic studies on the mouse cardiac parasympathetic nervous system. Zool. Pol. 2000; 45: 157-167. Not indexed in Pubmed.

3. Rysevaite K, Saburkina I, Pauziene N, et al. Morphologic pattern of the intrinsic ganglionated nerve plexus in mouse heart. Heart Rhythm. 2011; 8(3): 448-454, doi: 10.1016/j. hrthm.2010.11.019, indexed in Pubmed: 21075216.

4. Hasan W. Autonomic cardiac innervation: development and adult plasticity. Organogenesis. 2013; 9(3): 176-193, doi: 10.4161/org.24892, indexed in Pubmed: 23872607.

5. Kuder T, Nowak E. Autonomic cardiac nerves: literature review. Folia Morphol (Warsz). 2015; 74(1): 1-8, doi: 10.5603/ FM.2015.0003, indexed in Pubmed: 25792389.

6. Achanta S, Gorky J, Leung C, et al. A comprehensive integrated anatomical and molecular atlas of rat intrinsic cardiac nervous system. iScience. 2020; 23(6): 101140, doi: 10.1016/j. isci.2020.101140, indexed in Pubmed: 32460006.

7. Saburkina I, Rysevaite K, Pauziene N, et al. Epicardial neural ganglionated plexus of ovine heart: anatomic basis for experimental cardiac electrophysiology and nerve protective cardiac surgery. Heart Rhythm. 2010; 7(7): 942-950, doi: 10.1016/j. hrthm.2010.02.036, indexed in Pubmed: 20197118.

8. Day SM, Gu J, Polak JM, et al. Somatostatin in the human heart and comparison with guinea pig and rat heart. Br Heart J. 1985; 53(2): 153-157, doi: 10.1136/hrt.53.2.153, indexed in Pubmed: 2857086.

9. Marron K, Wharton J, Sheppard MN, et al. Human endocardial innervation and its relationship to the endothelium: an immunohistochemical, histochemical, and quantitative study. Cardiovasc Res. 1994; 28(10): 1490-1499, doi: 10.1093/ cvr/28.10.1490, indexed in Pubmed: 8001036.

10. Edwards FR, Hirst GD, Klemm MF, et al. Different types of ganglion cell in the cardiac plexus of guinea-pigs. J Physiol. 1995; 486 (Pt 2): 453-471, doi: 10.1113/jphysiol.1995. sp020825, indexed in Pubmed: 7473210.

11. Singh S, Johnson P, Lee R, et al. Topography of cardiac ganglia in the adult human heart. J Thoracic Cardiovasc Surgery. 1996; 112(4): 943-953, doi: 10.1016/s0022-5223(96)70094-6, indexed in Pubmed: 8873720.

12. Armour JA, Murphy DA, Yuan BX, et al. Gross and microscopic anatomy of the human cardiac nervous system. Anat Rec. 1997; 247: 289-298, doi: 10.1002/(SICI)10970185(199702)247:2<289::AID-AR15>3.0.CO-2-N, indexed in Pubmed: 9026008.

13. Pauza D, Skripkiene G, Skripka V, et al. Morphological study of neurons in the nerve plexus on heart base of rats and guinea pigs. J Auton Nerve Syst. 1997; 62(1-2): 1-12, doi: 10.1016/ s0165-1838(96)00102-6, indexed in Pubmed: 9021644.

14. Pauza D, Skripka V, Pauziene N, et al. Morphology, distribution, and variability of the epicardiac neural ganglionated subplexuses in the human heart. The Anatomical Record. 2000; 259(4): 353-382, doi: 10.1002/1097-0185(20000801)259:4<353::aidar10>3.0.co;2-r, indexed in Pubmed: 10903529.

15. Batulevicius D, Pauziene N, Pauza D. Topographic morphology and age-related analysis of the neuronal number of the rat intracardiac nerve plexus. Ann Anat - Anatomischer Anzeiger. 2003; 185(5): 449-459, doi: 10.1016/s0940-9602(03)80105-x, indexed in Pubmed: 14575272.

16. Pauza D, Pauziene N, Pakeltyte G, et al. Comparative quantitative study of the intrinsic cardiac ganglia and neurons in the rat, guinea pig, dog and human as revealed by histochemical staining for acetylcholinesterase. Ann Anat - Anatomischer Anzeiger. 2002; 184(2): 125-136, doi: 10.1016/s09409602(02)80005-x, indexed in Pubmed: 11936191.
17. Singh S, Johnson PI, Javed A, et al. Monoamine- and histamine-synthesizing enzymes and neurotransmitters within neurons of adult human cardiac ganglia. Circulation. 1999; 99(3): 411-419, doi: 10.1161/01.cir.99.3.411, indexed in Pubmed: 9918529.

18. Weihe E, Schütz B, Hartschuh W, et al. Coexpression of cholinergic and noradrenergic phenotypes in human and nonhuman autonomic nervous system. J Comp Neurol. 2005; 492(3): 370-379, doi: 10.1002/cne.20745, indexed in Pubmed: 16217790.

19. Martin L. Chinchillas as experimental models. The laboratory rabbit, guinea pig, hamster, and other rodents. 2012: 10091028, doi: 10.1016/b978-0-12-380920-9.00043-2.

20. Mikkelsen E, Lauridsen H, Nielsen PM, et al. The chinchilla as a novel animal model of pregnancy. R Soc Open Sci. 2017; 4(4): 161098, doi: 10.1098/rsos.161098, indexed in Pubmed: 28484627.

21. Suckow MA, Stevens KA, Wilson RP. The laboratory rabbit, guinea pig, hamster, and other rodents. 1st ed Saunders: Elsevier 2012.

22. Kuder T, Nowak E, Szczurkowski A, et al. A comparative study on cardiac ganglia in midday gerbil, Egyptian spiny mouse, chinchilla laniger and pigeon. Anat Histol Embryol. 2003; 32(3): 134-140, doi: 10.1046/j.1439-0264.2003.00445.x, indexed in Pubmed: 12823098.

23. Kuchinka J, Chrzanowska M, Kuder T. Adrenergic and cholinergic innervation of the atrioventricular valves in chinchilla (Chinchilla laniger). Folia Morphol (Warsz). 2017; 76(4): 590-595, doi: 10.5603/FM.a2017.0041, indexed in Pubmed: 28553858.

24. Radzimirska M, Kuchinka J, Nowak E, et al. Cholinergic and adrenergic innervation of the pancreas in chinchilla (Chinchilla Laniger Molina). Folia Histochem Cytobiol. 2020; 58(1): 54-60, doi: 10.5603/FHC.a2020.0005, indexed in Pubmed: 32202307.

25. Karnovsky MJ, Roots L. A „direct-coloring” thiocholine method for cholinesterases. J Histochem Cytochem. 1964; 12: 219-221, doi: 10.1177/12.3.219, indexed in Pubmed: 14187330.

26. Tsuji S, Larabi Y. A modification of thiocholine-ferricyanide method of Karnovsky and Roots for localization of acetylcholinesterase activity without interference by Koelle's copper thiocholine iodide precipitate. Histochemistry. 1983; 78(3): 317323, doi: 10.1007/BF00496619, indexed in Pubmed: 6193086.

27. Torre JCD. An improved approach to histofluorescence using the SPG method for tissue monoamines. J Neurosci Methods. 1980; 3(1): 1-5, doi: 10.1016/0165-0270(80)90029-1, indexed in Pubmed: 6164878.

28. Gage GJ, Kipke DR, Shain W. Whole animal perfusion fixation for rodents. J Vis Exp. 2012(65), doi: 10.3791/3564, indexed in Pubmed: 22871843.

29. Slaviková J, Kuncová J, Reischig J, et al. Catecholaminergic neurons in the rat intrinsic cardiac nervous system. Neurochem Res. 2003; 28: 593-598, doi: 10.1023/a:1022837810357, indexed in Pubmed: 12675149.

30. Hasan W, Smith PG. Modulation of rat parasympathetic cardiac ganglion phenotype and NGF synthesis by adrenergic nerves. Auton Neurosci. 2009; 145(1-2): 17-26, doi: 10.1016/j. autneu.2008.10.012, indexed in Pubmed: 19019738.

31. Haberberger R, Kummer W. beta 2-adrenoreceptor immunoreactivity in cardiac ganglia of the guinea pig. Histochem J. 1996; 28(11): 827-833, doi: 10.1007/BF02272155, indexed in Pubmed: 8968734.

32. Rysevaite K, Saburkina I, Pauziene N, et al. Immunohistochemical characterization of the intrinsic cardiac neural plexus 
in whole-mount mouse heart preparations. Heart Rhythm. 2011; 8(5): 731-738, doi: 10.1016/j.hrthm.2011.01.013, indexed in Pubmed: 21232628.

33. Richardson RJ, Grkovic I, Anderson CR. Immunohistochemical analysis of intracardiac ganglia of the rat heart. Cell Tissue Res. 2003; 314(3): 337-350, doi: 10.1007/s00441-003-0805-2, indexed in Pubmed: 14523644

34. Pauziene N, Alaburda P, Rysevaite-Kyguoliene K, et al. Innervation of the rabbit cardiac ventricles. J Anat. 2016; 228(1): 26-46, doi: 10.1111/joa.12400, indexed in Pubmed: 26510903.

35. Calupca MA, Locknar SA, Zhang L, et al. Distribution of cocaine- and amphetamine-regulated transcript peptide in the guinea pig intrinsic cardiac nervous system and colocalization with neuropeptides or transmitter synthetic enzymes. J Comp Neurol. 2001; 439(1): 73-86, doi: 10.1002/cne.1336, indexed in Pubmed: 11579383.

36. Scruggs P, Dun SL, Dun NJ. Cocaine- and amphetamine-regulated transcript peptide attenuates phenylephrine-induced bradycardia in anesthetized rats. Am J Physiol Regul Integr Comp Physiol. 2003; 285(6): R1496-R1503, doi: 10.1152/ ajpregu.00183.2003, indexed in Pubmed: 12933358.

37. Richardson RJ, Grkovic I, Anderson CR. Cocaine- and amphetamine-related transcript peptide and somatostatin in rat intracardiac ganglia. Cell Tissue Res. 2006; 324(1): 17-24, doi: 10.1007/s00441-005-0087-y, indexed in Pubmed: 16374620.

38. Mao P, Meshul C, Thuillier P, et al. CART Peptide is a potential endogenous antioxidant and preferentially localized in mitochondria. PLoS ONE. 2012; 7(1): e29343, doi: 10.1371/ journal.pone.0029343, indexed in Pubmed: 22235287.

39. Horackova M, Armour JA, Byczko Z. Distribution of intrinsic cardiac neurons in whole-mount guinea pig atria identified by multiple neurochemical coding. A confocal microscope study. Cell Tissue Res. 1999; 297(3): 409-421, doi: 10.1007/ s004410051368, indexed in Pubmed: 10460488.

40. Moravec M, Moravec J, Forsgren S. Catecholaminergic and peptidergic nerve components of intramural ganglia in the rat heart. An immunohistochemical study. Cell Tissue Res. 1990; 262(2): 315-327, doi: 10.1007/BF00309887, indexed in Pubmed: 1706221.

41. Parsons RL, Locknar SA, Young BA, et al. Presence and co-localization of vasoactive intestinal polypeptide with neu- ronal nitric oxide synthase in cells and nerve fibers within guinea pig intrinsic cardiac ganglia and cardiac tissue. Cell Tissue Res. 2006; 323(2): 197-209, doi: 10.1007/s00441-0050074-3, indexed in Pubmed: 16220273.

42. Steele PA, Gibbins IL, Morris JL, et al. Multiple populations of neuropeptide-containing intrinsic neurons in the guinea-pig heart. Neuroscience. 1994; 62(1): 241-250, doi: 10.1016/03064522(94)90327-1, indexed in Pubmed: 7816202.

43. Odorizzi M, Fernette B, Angel E, et al. Galanin receptor antagonists decrease fat preference in Brattleboro rat. Neuropharmacology. 2002; 42(1): 134-141, doi: 10.1016/s00283908(01)00115-0, indexed in Pubmed: 11750923.

44. Diaz Z, Narváez J, Hedlund $P$, et al. Centrally infused galanin-(1-15) but not galanin-(1-29) reduces the baroreceptor reflex sensitivity in the rat. Brain Research. 1996; 741(1-2): 32-37, doi: 10.1016/s0006-8993(96)00883-9, indexed in Pubmed: 9001701.

45. Herring N, Cranley J, Lokale MN, et al. The cardiac sympathetic co-transmitter galanin reduces acetylcholine release and vagal bradycardia: implications for neural control of cardiac excitability. J Mol Cell Cardiol. 2012; 52(3): 667-676, doi: 10.1016/j.yjmcc.2011.11.016, indexed in Pubmed: 22172449.

46. Crick SJ, Anderson RH, Ho SY, et al. Localisation and quantitation of autonomic innervation in the porcine heart II: endocardium, myocardium and epicardium. J Anat. 1999; 195 ( Pt 3): 359-373, doi: 10.1046/j.1469-7580.1999.19530359.x, indexed in Pubmed: 10580851.

47. Gordon L, Wharton J, Gaer JA, et al. Quantitative immunohistochemical assessment of bovine myocardial innervation before and after cryosurgical cardiac denervation. Cardiovasc Res. 1993; 27(2): 318-326, doi: 10.1093/cvr/27.2.318, indexed in Pubmed: 8097135.

48. Anker SD. Catecholamine levels and treatment in chronic heart failure. Eur Heart J. 1998; 19 Suppl F: F56-F61, indexed in Pubmed: 9651737.

49. Adameova A, Abdellatif Y, Dhalla NS. Role of the excessive amounts of circulating catecholamines and glucocorticoids in stress-induced heart disease. Can J Physiol Pharmacol. 2009; 87(7): 493-514, doi: 10.1139/y09-042, indexed in Pubmed: 19767873 .

Submitted: 2 June, 2021

Accepted after reviews: 23 September, 2021 Available as AoP: 28 September, 2021 